
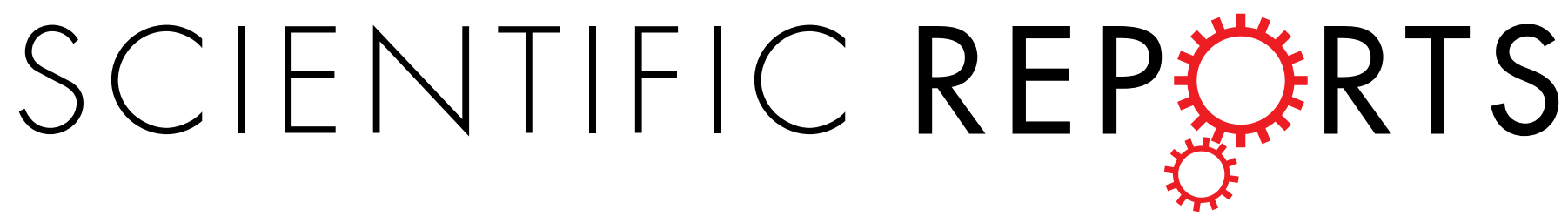

OPEN

\title{
Changes of flowering phenology and flower size in rosaceous plants from a biodiversity hotspot in the
}

Received: 21 October 2015

Accepted: 02 June 2016

Published: 17 June 2016

\section{past century}

\author{
Qin Yu ${ }^{1,2,3,4}$, Dong-Rui Jia ${ }^{5}$, Bin Tian ${ }^{1}$, Yong-Ping Yang ${ }^{1,2,3}$ \& Yuan-Wen Duan ${ }^{1,2,3}$
}

Responses of plant traits to climate changes are complex, which could be mirrored by the investigations of herbarium specimens. By examining specimens of Rosa and Cotoneaster species collected since $1920 \mathrm{~s}$ in Hengduan Mountains, we analyzed the changes of flowering phenology and flower size in the past century when climate changes were considered to be intensified. We found that flowering phenology of Rosa showed no significant change, but flowering phenology of Cotoneaster was delayed in recent years. Flower size of Rosa species showed a marginally significant decrease over the past century. The results suggested that responses of flowering time to global changes and pollinator mediated selection on floral traits might be more complex than what were expected. Our results indicated that future researches based on investigations of herbarium specimens should be carried out on multiple plant species with different flower structures and life histories to better understand the effects of climate changes on plant traits.

The global changes in the past century, mainly consisting of climate changes and intensified human activities, have been considered to be threatening biodiversity. Pollinators are a key component of global biodiversity and represent a key service for terrestrial ecosystems, which is vital to the maintenance of both wild plant communities ${ }^{1}$ and agricultural productivity ${ }^{2}$. There are compelling evidences of declines in pollinator richness and density at a global scale ${ }^{3}$, which has been attracting public and scientific concerns greatly since parallel declines were found in pollinators and insect-pollinated plant species ${ }^{4}$. However, it still remains unclear whether or not pollinator declines have driven the evolution of floral traits. Historical collections and/or records of plants and insects were useful to examine the population demographic changes in the time scale, such as plant traits ${ }^{5}$, plant flowering phenology $y^{6}$, pollinator richness and abundance ${ }^{7}$ and pollinator-plants interactions $s^{4,8,9}$. Therefore, examinations on flower size based on historical collections might reflect the selection by pollinators decline to a certain degree.

The Hengduan Mountains (HMs) in the Eastern Himalaya are considered to be the core region of the Himalaya hotspot, one of the global biodiversity hotspots ${ }^{10}$. The HMs, extending from north-west Yunnan, through west Sichuan and east Tibet, to south Qinghai, are renowned for their examples of phyletic radiations and concomitant high levels of endemic species and generic richness ${ }^{11}$. From 1920s to 2010s, the extensive and continuous collections of herbaria in this region by Chinese botanists provided an ideal opportunity to examine the changes of flowering phenology and flower size, which could jointly mirror the plant-pollinator relationships in the HMs in the past century. Accordingly, based on the investigations on herbaria of Rosa and Cotoneaster (Rosaceae) (Table 1), which were widely distributed in south part of the HM in northwest Yunnan province, we examined the changes of flowering phenology and flower size from 1920s to 2010s, with the aim of evaluating the effects of global changes on plants in the HMs in the past century.

${ }^{1}$ Key Laboratory for Plant Diversity and Biogeography of East Asia, Kunming Institute of Botany, Chinese Academy of Sciences, Kunming 650204, P. R. China. ${ }^{2}$ China Plant Germplasm and Genomics Center, Kunming Institute of Botany, Chinese Academy of Sciences, Kunming 650201, P. R. China. ${ }^{3}$ Institute of Tibetan Plateau Research at Kunming, Kunming Institute of Botany, Chinese Academy of Sciences, Kunming 650204, P. R. China. ${ }^{4}$ University of the Chinese Academy of Sciences, Beijing 100049, P. R. China. ${ }^{5}$ School of Ecology and Environmental Science, Yunnan University, Kunming 650091, P. R. China. Correspondence and requests for materials should be addressed to Y.-P.Y. (email: yangyp@mail.kib.ac.cn)orY.-W.D. (email: duanyw@mail.kib.ac.cn) 


\begin{tabular}{|l|c|c|l|}
\hline Species & Lowest altitude & Highest altitude & Aims \\
\hline R. longicuspis & 1600 & 3100 & Flower phenology, flower size \\
\hline R. omeiensis & 2200 & 4060 & Flower phenology, flower size \\
\hline R. sericea & 2350 & 3500 & Flower phenology, flower size \\
\hline R. soulieana & 2300 & 3500 & Flower phenology, flower size \\
\hline C. buxifolius & 1900 & 2800 & Flowering phenology \\
\hline C. dielsianus & 1690 & 3400 & Flowering phenology \\
\hline C. franchetii & 1560 & 3300 & Flowering phenology \\
\hline C. microphyllus & 1880 & 4400 & Flowering phenology \\
\hline C. pannosus & 1870 & 2700 & Flowering phenology \\
\hline C. poluninii & 1200 & 2700 & Flowering phenology \\
\hline C. subadpressus & 3100 & 3700 & Flowering phenology \\
\hline C. turbinatus & 1650 & 2700 & Flowering phenology \\
\hline
\end{tabular}

Table 1. Rosa and Cotoneaster species for flowering phenology and flower size and their altitudinal range.

\begin{tabular}{|c|c|c|c|c|c|}
\hline \multirow[b]{2}{*}{ Traits } & \multicolumn{2}{|c|}{ Standard coefficient } & \multirow[b]{2}{*}{$R$} & \multirow[b]{2}{*}{$\mathbf{F}$} & \multirow[b]{2}{*}{$P$} \\
\hline & Altitude & Year & & & \\
\hline Flowering phenology of Rosa & $0.22(0.02)$ & $-0.02(0.80)$ & 0.21 & 2.88 & 0.06 \\
\hline Flowering phenology of Cotoneaster & $0.33(<0.01)$ & $0.28(<0.01)$ & 0.41 & 10.56 & $<0.01$ \\
\hline Flower size of Rosa & $0.14(0.21)$ & $-0.22(0.06)$ & 0.25 & 2.44 & 0.09 \\
\hline
\end{tabular}

Table 2. Regression analysis of flowering phenology of Rosa and Cotoneaster, and flower size with altitude and year as explainable variables. Standard coefficients were shown with $\mathrm{P}$ values in the brackets, and significant relationships were labelled in bold.

\section{Results}

We found that flowering phenology of Rosa was delayed significantly with the increase of altitude, but showed no significant change in the past century (Table 2). In addition, flowering phenology of Cotoneaster was delayed with the increase of altitude and in recent years (Table 2). Flower size of Rosa species, indicated by the petal length, showed a marginally significant decrease over the past century, but no significant change was found in the flower size with the increase of altitude $(P=0.06$; Table 2$)$.

\section{Discussion}

Parallel to the global trend ${ }^{12}$, recent studies strongly suggested that the temperature increased significantly in the past century in the $\mathrm{HMs}^{13,14}$. Warming was considered to affect flowering phenology significantly, and there is a general trend of advanced phenology for both plants and animals ${ }^{15-17}$. However, in fact, experiments strongly suggested that the responses of plants were complex and species-dependent ${ }^{18-20}$. Although the flowering phenologies of Rosa and Cotoneaster species were delayed with the increase of altitude, indicating that temperature might still be one of the main factors affecting flowering time, they showed different changes in the past century. Specifically, flowering phenology of Cotoneaster species was delayed significantly in the recent years, but flowering phenology of Rosa species showed no significant changes. A recent study based on Rhododendron species from the HMs suggested that the flowering phenology showed no directional change over the past 45 years of rapid warming in this region, but responded significantly to the annual temperature deviation and the temperature deviation of the fall in the last years ${ }^{6}$. Therefore, our results emphasized the species dependent responses to warming in phonological events of plants, especially for the temperate trees whose flowering times are not primarily controlled by temperature ${ }^{21}$.

Pollination is an essential process in the sexual reproduction of seed plants, and about $88 \%$ of angiosperm species $^{22}$ and $70 \%$ of crop species ${ }^{2}$ rely on animal pollination. Globally, although the drivers of pollinator loss were complicated ${ }^{23}$, it was widely accepted that pollinator species and abundance declined significantly in the past century $^{2-4,7,8}$, which might result in the increased investment in plants to enhance attraction to pollinators. Large floral display size, consisting of flower size and number, was considered to be one of the most common strategy by plants to attract pollinators from a long distance ${ }^{24,25}$. However, flower size of Rosa species showed a decreasing trend in the past century, indicating a reduced investment on flower size in Rosa. This does not suggest a reduced attraction to pollinators because there are many flowers in blooming in Rosa species, which could contribute to the attractions to pollinators from a long distance. Accordingly, the reduced flower size of Rosa species might result from the reduced resource investments to flowers instead of selective pressures from the pollinators, but this speculation needs to be demonstrated in future researches.

Collectively, we suggested that responses of flowering time to global changes might be more complex than what were expected, and thus, under the backgrounds of global changes and pollinator decline $\mathrm{e}^{3}$ and intensified pollinator competition in biodiversity hotspots ${ }^{26}$, pollinator mediated selection on floral traits that could be influenced by climate changes ${ }^{27}$, should also be complex. Conclusively, to clarify the changes of flowering phenology 
and flower size in time scale in the past century, future researches based on investigations of herbaria should be carried out on multiple plant species with different flower structures, numbers and life histories, given that plant species might be experiencing various and different selective pressures.

\section{Methods}

We only located collections of Rosa and Cotoneaster that were preserved in herbaria of Kunming Institute of Botany (KUN) and occurred in northwest Yunnan province, including Nujiang, Dali, Lijiang and Diqing. Four criteria were applied to screen the herbaria: 1) the species should be collected in recent 10 years to ensure that we could get the recent data; 2) information, e.g. date of collection, altitude and phase (flowering and/or fruiting), should be specified; 3 ) only one herbarium should be employed for duplicate collections, which were made at the same time and same place; 4) the number of herbarium of each specie should be no less than 10. Four Rosa species and 7 Cotoneaster species were used for further analysis (Table 1). In total, 105 specimens of Cotoneaster species and 125 specimens of Rosa species were used to analyze flowering phenology, and 77 specimens of Rosa species were used for measurements of flower size.

As suggested by a previous study ${ }^{6}$, to combine the analysis across species, flowering time (day) and altitude (meters above sea level) of each collection were converted to within-species deviation from the mean. Specifically, flowering time was converted to relative flowering phenology by calculating days after $(+)$ or before $(-)$ mean collection date of each species, and altitude was also converted to relative altitude by calculating meters above $(+)$ or below (-) the species mean altitude.

Flower size was measured on Rosa species only because flowers of Cotoneaster species on specimens were too small to be measured correctly. Both length and width of one petal of a given flower that was kept finely were measured using a digital caliper. Also, to combine the analysis across species, we converted flowers size to the relative flower size by dividing the data on each herbarium specimens by the mean of each species.

To analyze the trends of plant traits with altitude in the past century, we performed a linear regression with plant traits, with relative flowering phenology and relative flower size as dependent variables and relative altitude and year as independent variables. Furthermore, a significant positive relationship between petal length and width were observed $(\mathrm{R}=0.61, P<0.01)$, so we used petal length as an indicator of flower size.

\section{References}

1. Aguilar, R., Ashworth, L., Galetto, L. \& Aizen, M. A. Plant reproductive susceptibility to habitat fragmentation: review and synthesis through a meta-analysis. Ecol. Lett. 9, 968-980 (2006).

2. Klein, A. M. et al. Importance of pollinators in changing landscapes for world crops. Proc. R. Soc. B-Biol. Sci. 274, 303-313 (2007)

3. Winfree, R., Bartomeus, I. \& Cariveau, D. P. Native pollinators in anthropogenic habitats. Ann. Rev. Ecol. Evol. Syst. 42, 1-22 (2011).

4. Biesmeijer, J. C. et al. Parallel declines in pollinators and insect-pollinated plants in Britain and the Netherlands. Science 313, 351-354 (2006)

5. Law, W. \& Salick, J. Human-induced dwarfing of Himalayan snow lotus, Saussurea laniceps (Asteraceae). Proc. Natl. Acad. Sci. USA $102,10218-10220(2005)$

6. Hart, R., Salick, J., Ranjitkar, S. \& Xu, J. C. Herbarium specimens show contrasting phenological responses to Himalayan climate. Proc. Natl. Acad. Sci. USA 111, 10615-10619 (2014).

7. Ollerton, J., Erenler, H., Edwards, M. \& Crockett, R. Extinctions of aculeate pollinators in Britain and the role of large-scale agricultural changes. Science 346, 1360-1362 (2014).

8. Burkle, L. A., Marlin, J. C. \& Knight, T. M. Plant-pollinator interactions over 120 years: Loss of species, co-occurrence, and function. Science 339, 1611-1615 (2013).

9. Miller-Struttmann, N. E. et al. Functional mismatch in a bumble bee pollination mutualism under climate change. Science 349, 1541-1544 (2015).

10. Myers, N., Mittermeier, R. A., Mittermeier, C. G., da Fonseca, G. A. B. \& Kent, J. Biodiversity hotspots for conservation priorities. Nature 403, 853-858 (2000).

11. Li, X.-W. \& Li, J. A preliminary floristic study on the seed plants from the region of Hengduan Mountain. Acta Bot. Yunn. 15, 217-231 (1993).

12. IPCC. Climate change 2013: The physical science basis. (Cambridge University Press, 2013).

13. Li, Z. S., Zhang, Q. B. \& Ma, K. P. Tree-ring reconstruction of summer temperature for A.D. 1475-2003 in the central Hengduan Mountains, Northwestern Yunnan, China. Clim. Change 110, 455-467 (2012).

14. Fan, Z. X., Brauning, A., Yang, B. \& Cao, K. F. Tree ring density-based summer temperature reconstruction for the central Hengduan Mountains in southern China. Glob. Planet. Change 65, 1-11 (2009).

15. Bartomeus, I. et al. Climate-associated phenological advances in bee pollinators and bee-pollinated plants. Proc. Natl. Acad. Sci. USA 108, 20645-20649 (2011)

16. Root, T. L. et al. Fingerprints of global warming on wild animals and plants. Nature 421, 57-60 (2003).

17. Wang, S. P. et al. Asymmetric sensitivity of first flowering date to warming and cooling in alpine plants. Ecology 95, 3387-3398 (2014).

18. Sherry, R. A. et al. Divergence of reproductive phenology under climate warming. Proc. Natl. Acad. Sci. USA 104, 198-202 (2007).

19. Cook, B. I., Wolkovich, E. M. \& Parmesan, C. Divergent responses to spring and winter warming drive community level flowering trends. Proc. Natl. Acad. Sci. USA 109, 9000-9005 (2012).

20. Miller-Rushing, A. J. \& Primack, R. B. Global warming and flowering times in Thoreau's concord: A community perspective. Ecology 89, 332-341 (2008).

21. Körner, C. \& Basler, D. Phenology under global warming. Science 327, 1461-1462 (2010).

22. Ollerton, J., Winfree, R. \& Tarrant, S. How many flowering plants are pollinated by animals? Oikos 120, 321-326 (2011).

23. Potts, S. G. et al. Global pollinator declines: trends, impacts and drivers. Trends Ecol. Evol. 25, 345-353 (2010).

24. Goodwillie, C. et al. Correlated evolution of mating system and floral display traits in flowering plants and its implications for the distribution of mating system variation. New Phytol. 185, 311-321 (2010).

25. Duan, Y. W., He, Y. P. \& Liu, J. Q. Reproductive ecology of the Qinghai-Tibet Plateau endemic Gentiana straminea (Gentianaceae), a hermaphrodite perennial characterized by herkogamy and dichogamy. Acta Oecol. 27, 225-232 (2005).

26. Vamosi, J. C. et al. Pollination decays in biodiversity hotspots. Proc. Natl. Acad. Sci. USA 103, 956-961 (2006).

27. Campbell, D. R. \& Powers, J. M. Natural selection on floral morphology can be influenced by climate. Proc. R. Soc. B-Biol. Sci. 282, 2015078 (2015). 


\section{Acknowledgements}

We are grateful to Prof. Hang Sun, Prof. Zhu-Liang Yang and Mrs. Jing-Hua Wang for their supports to our investigations in herbarium (KUN). This work was financially supported by 973 programs (2014CB954100) and NSFC (31570385).

\section{Author Contributions}

Y.-W.D. and Y.-P.Y. designed the research and wrote the manuscript; Q.Y. performed experiments; D.-R.J., B.T. and Y.-W.D analyzed data and prepared tables.

\section{Additional Information}

Competing financial interests: The authors declare no competing financial interests.

How to cite this article: Yu, Q. et al. Changes of flowering phenology and flower size in rosaceous plants from a biodiversity hotspot in the past century. Sci. Rep. 6, 28302; doi: 10.1038/srep28302 (2016).

(c) (i) This work is licensed under a Creative Commons Attribution 4.0 International License. The images or other third party material in this article are included in the article's Creative Commons license, unless indicated otherwise in the credit line; if the material is not included under the Creative Commons license, users will need to obtain permission from the license holder to reproduce the material. To view a copy of this license, visit http://creativecommons.org/licenses/by/4.0/ 